\title{
The knowledge and practice of universal precautions amongst midwives in Central Hospital, Benin City
}

\author{
Serah Osamudiamen Bolaji-Osagie ${ }^{1}$, Florence O. Adeyemo ${ }^{2 \star}$ and Olayinka. A Onasoga ${ }^{3}$ \\ ${ }^{1}$ School of Basic Medical Sciences, Department of Nursing Science, University of Benin, Benin, Edo State, Nigeria. \\ ${ }^{2}$ Department of Nursing, College of Health Sciences, Ladoke Akintola University of Technology, Osogbo, Osun state, \\ Nigeria. \\ ${ }^{3}$ Department of Maternal and Child Health Nursing, Faculty of Nursing, Niger Delta University, Wilberforce Island, \\ Bayelsa State, Nigeria.
}

Received 4 April, 2015; Accepted 7 October, 2015

\begin{abstract}
This study seeks to assess midwives' knowledge and practice of universal precautions in Central Hospital, Benin City. The study employed descriptive research design. The target population was all registered midwives in Central Hospital Benin City. A total number of 180 respondents were drawn from the total population using purposive sampling technique. A structured questionnaire containing 29 items was designed and developed. It was divided into 3 sections; section A to collect SocioDemographic Data, section B to ascertain the level of Knowledge of Universal Precautions among midwives under study and section $C$ designed to collect information about the Practice of Universal Precautions among the midwives under study. Data was scrutinized by experts to ensure face and content validity. Test re- test was used for reliability test which yielded $0.85 \mathrm{~h}$. Statistical Package for Social Sciences (SPSS) for windows 14.0 was used. For data analysis, descriptive statistics in the form of frequencies, percentages, Pearson product moment correlation was used. Level of significance was set at $5 \%(0.05)$ such that significant associations were established when $p<0.05$. The study revealed that knowledge of universal precautions amongst midwives and their practices of universal precautions are significantly high, because more than half of the midwives in the study area practices universal precautions while discharging their official duties. Findings also showed that there is significant association between knowledge of universal precautions and practice among midwives. If midwives continue to adhere strictly to universal precautions principles, then there will be less contamination of HIVIAIDS, hepatitis B as well as other blood infections.
\end{abstract}

Key words: Knowledge, practice, universal precautions, midwives.

\section{INTRODUCTION}

Healthcare workers (HCWs) are at risk of occupational

hazards. As they perform their clinical activities in the

*Corresponding author. E-mail: doc toradeyemo @yahoo.com.

Author(s) a gree that this article remain permanently open access under the terms of the $\underline{C}$ reative Commons Attribution Lic ense 4.0 Intemationa I License 
hospital, they are exposed to blood borne infections by pathogens, such as Human Immunodeficiency Virus (HIV), hepatitis B and hepatitis C Viruses, from sharps injuries and contacts with deep body fluids (Sadoh, et al., 2006). In an era of HIV epidemic in sub-Saharan Africa, occupational risk is real and significant. Pruss-Ustun et al. (2005) stated that developing countries account for the highest prevalence of HIV-infected patients in the world and the highest needle stick injuries. Orji et al. (2002) opined that needle stick injuries were the commonest occupational health hazard reported from a Nigerian teaching hospital. World Health Organization (2003) estimated that there are approximately 3 million cases of needle stick injury (NSI) in healthcare workers each year, with $90 \%$ of these occurring in developing countries.

Healthcare-acquired infections (HAls) are potentially life-threatening to health; it kills thousands of people every year, and burdens the medical industry with millions, if not billions of wasted dollars (Michelle, 2007). World Health Organization (2002) estimated that about $2.5 \%$ of HIV, $40 \%$ of hepatitis B and C cases that occurred among Healthcare workers worldwide is the result of exposures to occupational hazards. Nursing students are thought to be at high risk of needle-stick injury (NSI) due to poor technique inexperience and poor use of universal precautions (Ofili et al., 2003). The fact that blood and other body fluids from patients are becoming increasingly hazardous to healthcare providers, it has become a great concern to the public as well as health professionals all over the world. The practice of universal precautions as a way of safeguarding against possible infections in the workplaces had become more and more widely accepted by health workers (Bamigboye and Adesanya, 2006). Universal Precautions encompasses a wide range of steps taken during regular work day by healthcare workers and must be adhered to strictly in other to protect self, patients and co-workers from infection. It is important that all midwives routinely follow these precautions at anytime because there is possibility of coming in contact with patient's blood or body fluids during antenatal, labour or puerperium.

Universal Precautions are vital measures that have been adopted to help prevent health workers from being occupationally infected as well as reduce nosocomial infection. Midwives are envisaged to be caregivers to both mothers, foetus, infants and the family at large. Finding out their knowledge and practice of universal precautions will help reduce vulnerability to blood borne infections, promote healthy well being among individuals and to enhance their dreams as competent midwives in the society. In order to meet the millennium goals-4 (reduction of child mortality), 5 (improved maternal health), 6 (combat HIVIAIDS malaria and other diseases), it is important to access the knowledge and practice of universal precautions among midwives in Central hospital, Benin City.

\section{Statement of problem}

Midwives are at risk of being infected with blood-borne pathogens from clinical blood exposure through injuries with sharp instruments and needle sticks if universal precautions are not strictly adhered to. According to Tseko and Pilane (2006), occupational related HIV transmission among healthcare workers results mostly from needle pricks, blood and body fluid splashes. World Health Organization (2006) reports that among the 35 million health workers worldwide, about 3 million sustain percutaneous exposures to the blood borne pathogens each year, including 2 million to hepatitis B virus (HBV), 0.9 million to hepatitis C virus (HCV) and 170,000 to human immune deficiency virus (HIV). These injuries may result in 70,000 HBV, 15,000 HCV and 5,000 HIV infections. If these diseases are contracted by midwives, it may ruin their career, cause loss of interest in the profession and may stimulate nonchalant attitude in carrying out services. This has prompted the researcher to assess the knowledge and practice of universal precautions among midwives in Central Hospital, Benin City.

The broad objective for this study is to assess midwives knowledge and practice of universal precautions in Central Hospital, Benin City, to assess the level of knowledge of universal precautions among midwives in Central Hospital, Benin City, to determine the level of practice of universal precautions among midwives in Central Hospital, Benin City, to determine the knowledge of universal precautions amongst midwives in not significantly high and to determine the practice of universal precautions amongst midwives in not significantly high.

\section{Statement of hypotheses}

There is no significant association between knowledge of universal precautions and practice among midwives.

\section{METHODOLOGY}

Descriptive research design was employed in this study. The Central hospital, Benin City where the study was done is located in zone A, ward 1 of Oredo Local government area in Benin City, Edo State. It is bounded on the west by Federal prisons, separated by Sapele road and the east by Oba palace separated by airport road. There is a major round about adjacent to the hospital known as Ring road and behind it is Ezoti Street. Staff strength of the hospital is seven hundred and twenty working in twenty-six departments. There are thirty-two units of which eight of the units are for maternal and child healthcare services. There are four hundred and twenty 
bed spaces and two hundred and seventy one nurses-midwives working in these units of the hospital. The target population for this study included all registered midwives in Central hospital Benin City.

\section{Sample size and sampling technique}

A total number of 180 respondents were drawn from the total population using purposive sampling technique from the thirty-two units in the hospital. Data was collected from all midwives with the use of questionnaire.

\section{Instrument for data collection}

After a thorough review of literature, a structured questionnaire was designed and developed with 29 items, containing qualitative and quantitative information on universal precautions among midwives. It was divided into 3 sections; section A to collect SocioDemographic Data, section B to elicit the level of Knowledge of universal precautions among midwives under study and section $C$ designed to collect information about the Practice of Universal Precautions among the midwives under study.

\section{Validity/reliability of instrument}

The questionnaire developed was thoroughly scrutinized by experts to ensure face and content validity. Test re-test was used for reliability test which yielded $0.85 \mathrm{~h}$.

\section{Method of data collection}

The midwives were asked to fill the questionnaires and returned. The data was collected over a period of four weeks in a period of 5 working days between the hours of 8 to 4 .

\section{Method of data analysis}

Data collected was entered into the computer using Statistical Package for Social Sciences (SPSS) for windows 14.0. Both descriptive and inferential statistics were used to analyze the data collected. Descriptive statistics in the form of frequencies, percentages, Pearson product moment correlation. Level of significance was set at $5 \%(0.05)$ such that significant associations were established when $p<0.05$.

\section{Ethical consideration}

Permission was granted by the Assistant Director of Nursing in Central Hospital Benin City. The study and its purpose were explained to the respondents (midwives) and all information gathered from respondents were treated confidentially.

\section{RESULTS}

\section{Socio-demographic characteristics}

Table 1 reveals that majority of the respondents 50
(27.8\%) were between 31 and 40 years, 51 to 60 years, $35(19.4 \%)$ of them were between 21 and 30 years, while $45(25.0 \%)$ of the respondents were between age 41 to 50 years. Females comprised 168 (93.3\%) of the group. With respect to marital status, majority of the respondents were married $130(72.2 \%), 20(11.1 \%)$ are singles while $30(16.7 \%)$ were widows.

Majority of the midwives were Chief nursing officers and Nursing officers I with 40 (22.2\%), 38 (21.1\%) were Nursing officers II, 20 (11.1\%) were Assistant Chief nursing officers, 15 (8.3\%) and 7 (4.0\%) were Principal nursing officers, 165 (91.7\%) were Christians. Majority 84 $(46.7 \%)$ of the midwives were Bini while the least were Hausa 3 (1.7\%) and other tribes 30 (16.7\%).

\section{Research question one}

Is the knowledge of universal precautions amongst midwives not significantly high? Population t-test was employed to answer this research question, since it was a one variable research question, the result of the responses of respondents were computed and is presented in Table 1 . The result presented in Table 2 is to assess level of knowledge among midwives in universal precautions. As presented in Table 2, the sample mean of 17.03 is greater than the population mean of 12.00 at 179 degree of freedom, this result implies that this research question which sought to find out knowledge of universal precautions amongst midwives is significantly high therefore more than half of the midwives in the study area seem to have knowledge of universal precautions.

\section{Research question two}

The practice of universal precautions among midwives is not significantly high? Population t-test was employed to answer this research question, since it was a one variable research question, the result of the responses of respondents were computed and is presented in Table 3 . The result presented in Table 3 assessed the level of universal precautions practiced among midwives. As presented in Table 3, the sample mean of 15.98 is greater than the population mean of 14.15 at 179 degree of freedom, $p<.05$ this result implies that this research question which sought to find out midwives practices of universal precautions is significantly high, therefore more than half of the midwives in the study area practices universal precautions while discharging their official duties.

\section{Hypothesis one}

There is no significant association between knowledge of 
Table 1. Frequency distribution of socio-demographic characteristics of midwives in Central Hospital, Benin City.

\begin{tabular}{|c|c|c|c|}
\hline \multirow{2}{*}{ Demographic data } & \multicolumn{2}{|c|}{ Respondents in this study $(\mathrm{N}=180)$} & \multirow{2}{*}{ Percent } \\
\hline & Variable & Frequency $(\mathrm{N})$ & \\
\hline \multirow{4}{*}{ Age (years) } & $21-30$ & 35 & 19.4 \\
\hline & $31-40$ & 50 & 27.8 \\
\hline & $41-50$ & 45 & 25.0 \\
\hline & $51-60$ & 50 & 27.8 \\
\hline \multirow{2}{*}{ Sex } & Male & 12 & 6.7 \\
\hline & Female & 168 & 93.3 \\
\hline \multirow{3}{*}{ Marital status } & Single & 20 & 11.1 \\
\hline & Married & 130 & 72.2 \\
\hline & Widow & 30 & 16.7 \\
\hline \multirow{7}{*}{ Rank } & Assistant director of nursing service & 7 & 4.0 \\
\hline & Chief nursing officers & 40 & 22.2 \\
\hline & Assistant chief nursing officers & 20 & 11.1 \\
\hline & Principal nursing officers & 15 & 8.3 \\
\hline & Senior nursing officers & 20 & 11.1 \\
\hline & Nursing officers 1 & 40 & 22.2 \\
\hline & Nursing officers 11 & 38 & 21.1 \\
\hline \multirow{3}{*}{ Religion } & Christianity & 165 & 91.7 \\
\hline & Islam & 10 & 5.5 \\
\hline & Traditional & 5 & 2.8 \\
\hline \multirow{5}{*}{ Ethnicity } & Bini & 84 & 46.7 \\
\hline & Yoruba & 27 & 15.0 \\
\hline & Ibo & 36 & 20.0 \\
\hline & Hausa & 3 & 1.7 \\
\hline & Others & 30 & 16.7 \\
\hline
\end{tabular}

Table 2. Population t-test of midwives knowledge of universal precautions.

\begin{tabular}{lccccc}
\hline Groups & N & Mean & SD & t-test & Significance \\
\hline Sample mean & 180 & 17.03 & 2.55 & - & - \\
Population mean & - & 12.00 & - & 166.03 & 0.002 \\
\hline
\end{tabular}

Table 3. Population t-test of midwives practices of universal precautions.

\begin{tabular}{lccccc}
\hline Groups & N & Mean & SD & t-test & Significance \\
\hline Sample mean & 180 & 15.98 & 2.83 & 156.23 & 0.004 \\
Population mean & - & 14.15 & - & - & - \\
\hline
\end{tabular}

universal precautions and practice among midwives, Pearson Product moment correlation was used to test this hypothesis at $p<0.05$, the result is presented in Table 3. As presented in Table 4, the calculated r-value 
Table 4. Pearson product moment correlation of knowledge and practice of universal precautions among midwives.

\begin{tabular}{lccccc}
\hline Variables & N & Mean & SD & r-value & Significance \\
\hline Knowledge of universal precaution & 180 & 14.82 & 2.43 & $0.68^{*}$ & 0.000 \\
Practice of universal precautions & 180 & 12.45 & 2.12 & - & - \\
\hline
\end{tabular}

*significant at $p<.05 ; \mathrm{df}=178 ;$ critical r-value $=0.138$.

of 0.68 is greater than the critical r-value of 0.138 at 178 degree of freedom. This result implies that the null hypothesis which states that there is no significant association between knowledge of universal precautions and practice among midwives is rejected while the alternate is upheld, there is no association between midwives attitude towards universal precaution.

\section{DISCUSSION}

This study has attempted to assess the knowledge and practice of universal precautions among Midwives in Central Hospital, Benin City. The socio-demographic characteristics showed that majority $50(27.8 \%)$ of the midwives were between the ages of 31 to 40 years and 51 to 60 years which implies that they were of their prime age. Majority of the respondents were females, this may be due to the fact that people believe that midwifery is a female profession since it involves women and childbearing. Majority of them were married and were of a lower and higher cadre. It was also revealed that the Christians and the Bini's predominate the organization. Majority of them have had a work experience of between one to ten years.

The study revealed that knowledge of universal precautions amongst midwives is significantly high. This is in contrast with the findings of Ofili et al. (2003) in a study carried out among nurses in Central Hospital, Benin City, that the nurses had a poor knowledge about universal precautions as only $34.2 \%$ of nurses had heard about universal precautions. Furthermore, Gammon (2005) stated that globally, knowledge of universal precautions is inadequate and compliance is low. Most of the respondents have had previous training on universal precautions which may have influenced their knowledge positively

The findings of this study also showed that midwives practices of universal precautions is significantly high, because more than half of the midwives in the study area practices universal precautions while discharging their official duties. This finding is consistent with Ferguson et al. (2006) that majority of their respondents believed that stopping to use standard precautions would have put the patient at risk in a study carried out among community hospital-based healthcare workers on reasons for not using precautions. Also, this study is inconsistent with Deloy et al. (2005) that majority of the respondents accepted that they adhere to universal precaution rules while a few others do not. The study revealed that there is significant association between knowledge of universal precautions and practice among midwives. This finding does not corroborate with the study of Chan et al. (2002) whose study showed no significant association between the nurses knowledge and compliance with Universal Precaution.

\section{Implications of universal precautions for midwifery practice}

Universal precautions will help prevent midwives from infections. The knowledge and practice of universal precautions in midwifery practice will not only prevent midwives from infections but every health workers, clinical students, patients as well as nurses aids. This study will also give insight to midwives to adhere strictly to universal precautions as professional nurses and midwives as well as in other health related field.

\section{SUMMARY}

This study was designed to assess the knowledge and practice of universal precaution among midwives in Central Hospital, Benin City. This study reveals that, majority $(85.1 \%)$ of the respondents were between the age of 31 to 40 years and 51 to 60 years and of a lower and higher cadre, there were more female midwives in the organization than male, majority of them were married and were Christians. The Bini's were the predominant ethnic group. The findings of this shows midwives level of knowledge and practice of universal precaution was high.

\section{CONCLUSION}

Universal precautions are vital measures that have been adopted to help prevent health workers from being infected in the line of duty. The knowledge and practice of 
universal precautions has been shown to prevent majority of healthcare workers from blood borne infections, if midwives continues to adhere strictly to universal precautions principles, then there will be less contamination of HIVIAIDS, hepatitis B as well as other blood infections. Knowledge is not enough to prevent infections but adequate skills during practice is very pertinent.

\section{RECOMMENDATIONS}

Based on the findings of this study the following recommendations were made:

1) This study suggests that more personal protective equipment should be provided in all health institution by the government.

2) Strategies to promote the use of universal precautions which take into account behaviour change and accrual of knowledge including its integration into practice should be incorporated into all school's curriculum.

3) Nurse-Midwives' Managers and occupational health workers should take a leadership role to ensure that safe practices are used in the care of patients.

4) Obligatory training programme in universal precautions for all nurses and midwives should be provided in all healthcare organizations.

5) Implementation of policies on universal precautions for strict adherence is essential.

6) A system for monitoring the appropriate use of personal protective equipment is essential in nursemidwifery programmes.

\section{Conflicts of interest}

Authors have none to declare.

\section{REFERENCES}

Bamigboye A, Adesanya A (2006). Knowledge and Practice of Universal Precautions Among Qualifying Medical and Nursing Students: A Case Study of Obafemi Awolowo, University Teaching Hospitals Complex, Ile Ife. Res. J. Med. Med. sci. 1(3):112-117.

Chan R, Molassiotis A, Chan E, Chan V, Ho B, Lai CY, Lam P, Shit F, Yiu I (2002). Nurse Knowledge of and compliance with universal precaution in an acute care hospital. Int. J. Nurs. Stud. 39:157-163.

Deloy D, Searcy C, Murphy L, Gershon R (2005). Behavioral-diagnostic analysis of compliance with universal precautions among nurses. J. Occup. Health Psychol. 5(1):127-41.

Ferguson K, Beekmann S, Doebbeling E (2006). Critical Incidents of Non adherence with Standard Precautions Guidelines Among Community Hospital-based Health Care Workers, J. Gen. Intern. Med. 19:726-731.

Gammon J (2005). A review of knowledge, compliance and strategies to improve practice, Health Science Swansea Institute of Higher Education J. Res. Nurs. 10(5):529-547.

Michelle B (2007). Aseptic technique: No Major Changes but More Important than Ever. Mayo Clinic Rochester, MN, USA.

Ofili A, Asuzu M, Okojie O (2003). Knowledge and practice of universal precaution amongst nurses in Central Hospital, Benin City, Edo State, Nigeria. Niger Postgrad. Med. J. 10:26-31.

Orji E, Fasubaa O, Onwudiegwu U (2002) Occupational health hazards among health care workers in an Obstetric and Gynaecological unit of a Nigerian Teaching hospital. J. Obstet. Gynaecol. 22:75-78.

Pruss-Ustun A, Rapiti E, Hutin Y (2005). Estimation of the global burden of disease attributable to contaminated sharps injuries among healthcare workers. Am. J. Ind. Med. 48(6):482-490.

Sadoh W, Fawole A, Sadoh A, Oladimeji A, Sotiloye O (2006). Practice of universal precautions among health workers, Original Communication, Benin, Ibadan, and Abeokuta, Nigeria. J. Natl. Med. Assoc. 98(5):722-726.

Tseko G, Pilane C (2006). The nurse-midwife and use of universal precautions at a health facility in Botswana: implications for nurse training. : AIDS 2006 - XVI International AIDS Conference: Abstract no. CDC0799"

World Health Organization (2002). The world health report: reducing risks, promoting health life. World Health Organization, Geneva.

World Health Organization (2006) universal precautions, including injection safety. Available at: http://www.who.int/hiv/topics/precautions/universal/en/.

World Health Organization (2003). Aide memoire for a strategy to protect health workers from infection with blood borne viruses. Geneva 